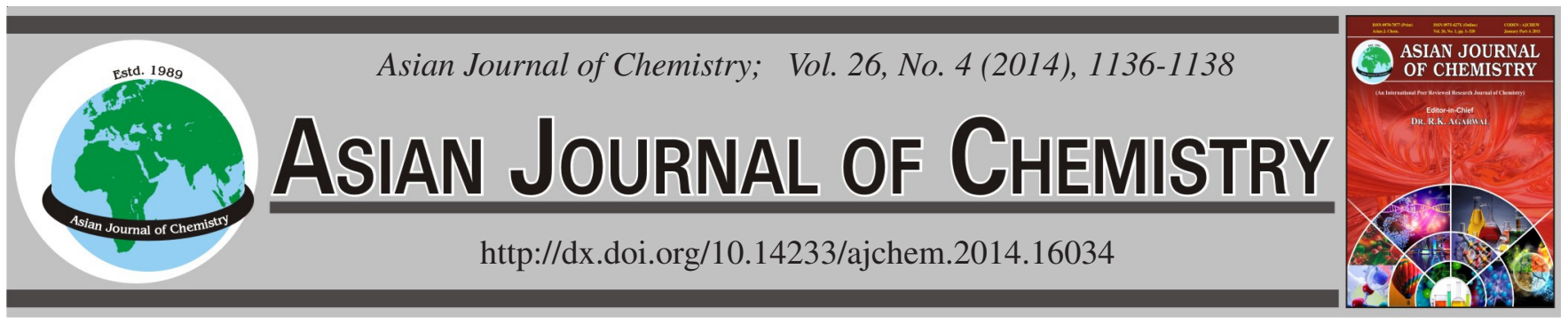

\title{
Synthesis and Characterization of Tetrahalogen Substituted Salamo-type Bisoximes Possessing More Flexible O-Alkyl Chain
}

\author{
Yu-Hua Yang, Gang Li*, Xiu-Yan Dong, Yu-Jie Zhang and Meng-Meng Zhao
}

School of Chemical and Biological Engineering, Lanzhou Jiaotong University, Lanzhou 730070, P.R. China

*Corresponding author: E-mail: li_gang78@126.com

\begin{abstract}
Four tetrahalogen substituted Salamo-type bisoximes $\mathrm{H}_{2} \mathrm{~L}^{1}-\mathrm{H}_{2} \mathrm{~L}^{4}$ have been synthesized from 3-bromo-5-chloro-2-hydroxybenzaldehyde and 1,7-bis(aminooxy)heptane, 1,8-bis(aminooxy)octane, 1,9-bis(aminooxy)nonane or 1,10-bis(aminooxy)decane in ethanol medium, respectively and characterized by elemental analyses as well as IR, UV-visible and ${ }^{1} \mathrm{H}$ NMR spectroscopy. Salamo-type bisoxime compound is much more useful to assemble supramolecular systems than a Salen moiety.
\end{abstract}

Keywords: Salamo-type bisoxime, Synthesis, Characterization.

\section{INTRODUCTION}

$\mathrm{H}_{2}$ Salen [N,N-bis(salicylidene)ethylenediamine] derivatives have played a pivotal role in the development of modern coordination chemistry ${ }^{1-4}$. In particular, $\mathrm{H}_{2}$ Salen-type compounds capable of coordinating to metal ions, are important for the investigation of supramolecular interactions ${ }^{5}$. These substances have also been used for various applications, such as various organic reaction processes as catalysts, models of reaction centers of metalloenzymes and nonlinear optical materials ${ }^{6}$. Numerous researchers have used Schiff-base condensation as the reaction step to synthesize $\mathrm{H}_{2}$ Salen-type compounds, often in high yield ${ }^{7}$. With the goal of developing $\mathrm{H}_{2}$ Salen-type compounds that could coordinate to multiple metals and be easily prepared, we identified $\mathrm{H}_{2}$ Salamo-type compounds as an attractive target. If an $\mathrm{O}$-alkyl oxime moiety $\left(-\mathrm{CH}=\mathrm{N}-\left(\mathrm{CH}_{2}\right)_{\mathrm{n}}-\mathrm{N}=\mathrm{CH}-\right)$ is used instead of a Schiff base $\left(-\mathrm{CH}=\mathrm{N}-\mathrm{O}-\left(\mathrm{CH}_{2}\right)_{\mathrm{n}}-\mathrm{O}-\mathrm{N}=\mathrm{CH}-\right)$, the larger electronegativity of oxygen atoms is expected to affect strongly the electronic properties of $\mathrm{N}_{2} \mathrm{O}_{2}$ coordination sphere, which can lead to different and novel properties and structures of the resulted complexes $^{8-10}$. In this paper, we report the synthesis and spectroscopic properties of a series of multihalogen substituted Salamo-type compounds, which bearing two salicylidene moieties and two O-alkyloxime linkages.

\section{EXPERIMENTAL}

3-Bromo-5-chloro-2-hydroxybenzaldehyde, 1,7-dibromoheptane, 1,8-dibromoctane, 1,9-dibromnonane and 1,10-dibromodecane $(\geq 99 \%)$ were purchased from Alfa Aesar and used without further purification. The other reagents and solvents were analytical grade reagents from Tianjin Chemical Reagent Factory. C, $\mathrm{H}$ and $\mathrm{N}$ analyses were carried out with a $\mathrm{GmbH}$ VariuoEL V3.00 automatic elemental analyzer. IR spectra were recorded on a VERTEX70 FT-IR spectrophotometer using $\mathrm{KBr}$ pellets. UV/visible absorption spectra were recorded on a Shimadzu UV-2550 spectrometer. ${ }^{1} \mathrm{H}$ NMR spectra were recorded on a Mercury-400BB spectrometer. Melting points were measured by the use of a microscopic melting point apparatus made in Beijing Taike Instrument Limited Company and the thermometer was uncorrected.

Preparation of 4,4'-dichloro-6,6'-dibromo-2,2'-[(1,7heptanediyldioxy)bis(nitrilomethylidyne)]diphenol $\left(\mathbf{H}_{2} \mathbf{L}^{1}\right)$ : Synthetic route to Salamo-type bisoxime $\mathrm{H}_{2} \mathrm{~L}^{1}$ is shown in Scheme-I. 1,7-bis(Aminooxy)heptane was synthesized according to an analogous method reported earlier ${ }^{10,11}$.

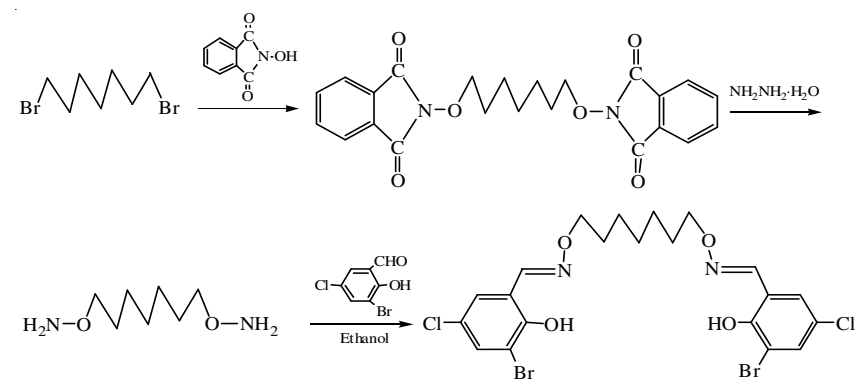

Scheme-I: Synthesis of Salamo-type bisoximes $\mathrm{H}_{2} \mathrm{~L}^{1}$

To an ethanolic solution $(8 \mathrm{~mL})$ of 3-bromo-5-chloro2-hydroxybenzaldehyde (94 $\mathrm{mg}, 0.40 \mathrm{mmol}$ ) was added an 
ethanolic solution $(3 \mathrm{~mL})$ of 1,7-bis(aminooxy)heptane $(32.0$ $\mathrm{mg}, 0.20 \mathrm{mmol})$. After the solution had been stirred at $55^{\circ} \mathrm{C}$ for $4 \mathrm{~h}$, When cooled to room temperature, the white precipitate was filtered and washed successively with ethanol/hexane and hexane, respectively. The product was dried under reduced pressure to obtain white crystalline solid $\mathrm{H}_{2} \mathrm{~L}^{1}$.

Preparation of 4,4'-dichloro-6,6'-dibromo-2,2'-[(1,8octanediyldioxy)bis(nitrilomethylidyne)]diphenol $\left(\mathbf{H}_{2} \mathbf{L}^{2}\right)$ : Synthetic route to Salamo-type bisoxime $\mathrm{H}_{2} \mathrm{~L}^{1}$ is shown in Scheme-II. 1,8-bis(Aminooxy)octane was synthesized according to an analogous method reported earlier ${ }^{10,11}$.

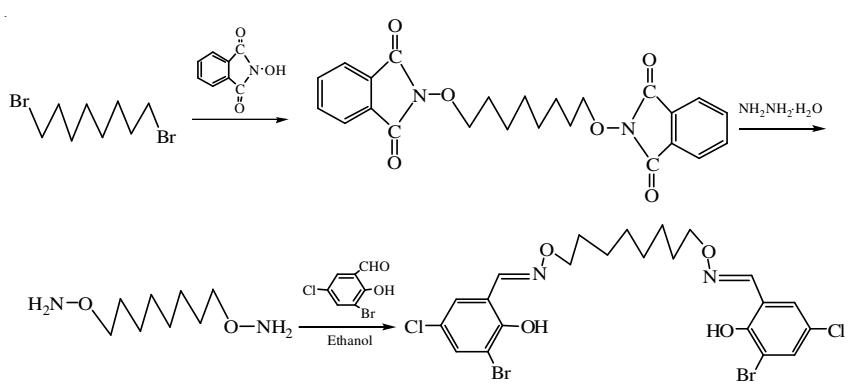

Scheme-II: Synthesis of Salamo-type bisoximes $\mathrm{H}_{2} \mathrm{~L}_{2}$

To an ethanolic solution (8 mL) of 3-bromo-5-chloro-2hydroxybenzaldehyde $(103.0 \mathrm{mg}, 0.44 \mathrm{mmol})$ was added an ethanolic solution (3 mL) of 1,8-bis(aminooxy)octane (37.0 $\mathrm{mg}, 0.21 \mathrm{mmol})$. After the solution had been stirred at $55^{\circ} \mathrm{C}$ for $4 \mathrm{~h}$, The formed precipitate was separated by filtration and washed successively with ethanol/hexane and hexane, respectively. The product was dried under reduced pressure to obtain pale-yellow solid $\mathrm{H}_{2} \mathrm{~L}^{2}$.

Preparation of 4,4'-dichloro-6,6'-dibromo-2,2'-[(1,9nonanediyldioxy)bis(nitrilomethylidyne)]diphenol $\left(\mathbf{H}_{2} \mathbf{L}^{3}\right)$ : Synthetic route to Salamo-type bisoxime $\mathrm{H}_{2} \mathrm{~L}^{3}$ is shown in Scheme-III. 1,9-bis(Aminooxy)nonane was synthesized according to an analogous method reported earlier ${ }^{10,11}$.

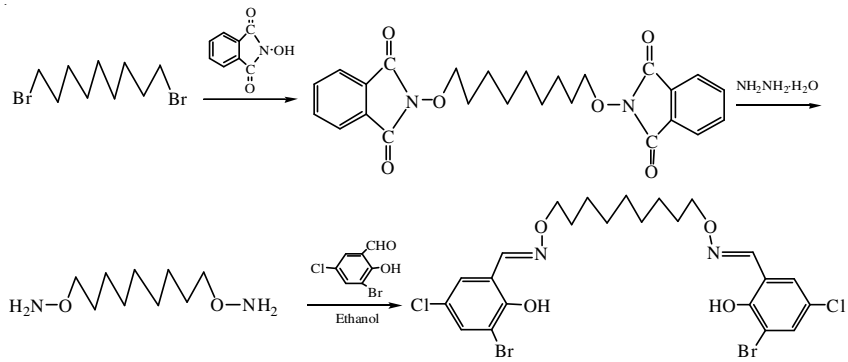

Scheme-III: Synthesis of Salamo-type bisoximes $\mathrm{H}_{2} \mathrm{~L}^{3}$

To an ethanolic solution (8 mL) of 3-bromo-5-chloro-2hydroxybenzaldehyde $(95.0 \mathrm{mg}, 0.40 \mathrm{mmol})$ was added an ethanol solution $(3 \mathrm{~mL})$ of 1,9-bis(aminooxy)nonane (38.1 $\mathrm{mg}, 0.20 \mathrm{mmol})$. After the solution had been stirred at $55^{\circ} \mathrm{C}$ for $4 \mathrm{~h}$, the mixture was filtered, washed successively with ethanol/ hexane and hexane, respectively. The product was dried under reduced pressure to obtain white crystalline solid $\mathrm{H}_{2} \mathrm{~L}^{3}$.

Preparation of 4,4'-dichloro-6,6'-dibromo-2,2' - [(1,10decanediyldioxy)bis (nitrilomethylidyne) $]$ diphenol $\left(\mathrm{H}_{2} \mathrm{~L}^{4}\right)$ : Synthetic route to Salamo-type bisoxime $\mathrm{H}_{2} \mathrm{~L}^{1}$ is shown in Scheme-IV. 1,10-bis(Aminooxy)decane was synthesized according to an analogous method reported earlier ${ }^{10,11}$.

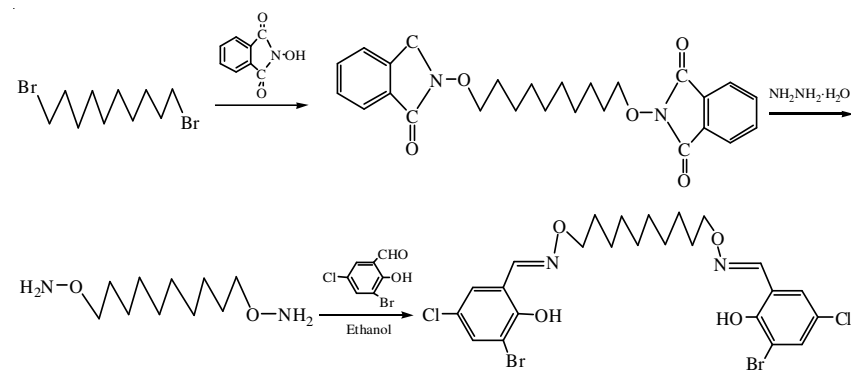

Scheme-IV: Synthesis of Salamo-type bisoximes $\mathrm{H}_{2} \mathrm{~L}^{4}$

To an ethanolic solution ( $8 \mathrm{~mL}$ ) of 3-bromo-5-chloro-2hydroxybenzaldehyde $(126.0 \mathrm{mg}, 0.54 \mathrm{mmol})$ was added an ethanolic solution ( $3 \mathrm{~mL}$ ) of 1,10-bis(aminooxy)decane (54 mg, $0.26 \mathrm{mmol}$ ). After the solution had been stirred at $55^{\circ} \mathrm{C}$ for $4 \mathrm{~h}$, the mixture was filtered, washed successively with ethanol/hexane and hexane, respectively. The product was dried under reduced pressure to obtain white crystalline solid $\mathrm{H}_{2} \mathrm{~L}^{4}$.

\section{RESULTS AND DISCUSSION}

A series of multihalogen substituted Salamo-type bisoximes $\mathrm{H}_{2} \mathrm{~L}^{1}-\mathrm{H}_{2} \mathrm{~L}^{4}$ have been synthesized with good yields and the composition are confirmed by elemental analyses, IR, UV-visible spectra and ${ }^{1} \mathrm{H}$ NMR data.

The colour, yields, melting points and elemental analytical results of the synthesized Salamo-type bisoxime compounds $\mathrm{H}_{2} \mathrm{~L}^{1}-\mathrm{H}_{2} \mathrm{~L}^{4}$ are presented in Table-1. Their compositions agree with the formulae. All the compounds are white microcrystalline solid, stable in air and soluble in hot DMF and DMSO, insoluble in methanol, ethanol, acetone, acetonitrile, chloroform, dichloromethane, tetrahydrofuran, $n$-hexane, ether and water.

IR spectra of multihalogen substituted Salamo-type bisoxime compounds $\mathrm{H}_{2} \mathrm{~L}^{1}-\mathrm{H}_{2} \mathrm{~L}^{4}$ are given in Table-2. In the IR spectra of the title compounds $\mathrm{H}_{2} \mathrm{~L}^{1}-\mathrm{H}_{2} \mathrm{~L}^{4}$, the bands due to characteristic $\mathrm{C}=\mathrm{N}$ stretching absorption bands appear at 1604$1602 \mathrm{~cm}^{-1}$, respectively ${ }^{11,12}$. The Ar-O stretching frequencies

\begin{tabular}{|c|c|c|c|c|c|c|c|}
\hline \multirow{3}{*}{ Comp. } & \multicolumn{7}{|c|}{$\begin{array}{l}\text { TABLE-1 } \\
\text { COLOUR, YIELDS, MELTING POINTS AND ANALYTICAL DATA OF } \\
\text { TETRAHALOGEN SUBSTITUTED SALAMO-TYPE BISOXIMES } \mathrm{H}_{2} \mathrm{~L}^{1}-\mathrm{H}_{2} \mathrm{~L}^{4}\end{array}$} \\
\hline & \multirow{2}{*}{ Colour } & \multirow{2}{*}{ m.p. $\left({ }^{\circ} \mathrm{C}\right)$} & \multirow{2}{*}{ Yield (\%) } & \multirow{2}{*}{ m.f. (m.w.) } & \multicolumn{3}{|c|}{ Elemental analysis (\%): Found (Calcd.) } \\
\hline & & & & & $\mathrm{C}$ & $\mathrm{H}$ & $\mathrm{N}$ \\
\hline $\mathrm{H}_{2} \mathrm{~L}^{1}$ & White & $205-206$ & 65.2 & $\mathrm{C}_{21} \mathrm{H}_{22} \mathrm{~N}_{2} \mathrm{O}_{4} \mathrm{Br}_{2} \mathrm{Cl}_{2}(597.1)$ & $42.14(42.24)$ & $3.73(3.71)$ & $4.69(4.69)$ \\
\hline $\mathrm{H}_{2} \mathrm{~L}^{2}$ & White & $211-212$ & 70.1 & $\mathrm{C}_{22} \mathrm{H}_{24} \mathrm{~N}_{2} \mathrm{O}_{4} \mathrm{Br}_{2} \mathrm{Cl}_{2}(611.2)$ & $43.13(43.24)$ & $4.10(3.96)$ & $4.57(4.58)$ \\
\hline $\mathrm{H}_{2} \mathrm{~L}^{3}$ & White & $213-215$ & 68.7 & $\mathrm{C}_{23} \mathrm{H}_{26} \mathrm{~N}_{2} \mathrm{O}_{4} \mathrm{Br}_{2} \mathrm{Cl}_{2}(625.2)$ & $44.17(44.19)$ & $4.08(4.19)$ & $4.63(4.48)$ \\
\hline $\mathrm{H}_{2} \mathrm{~L}^{4}$ & White & $221-222$ & 78.1 & $\mathrm{C}_{24} \mathrm{H}_{28} \mathrm{~N}_{2} \mathrm{O}_{4} \mathrm{Br}_{2} \mathrm{Cl}_{2}(639.2)$ & $44.84(45.10)$ & $4.26(4.42)$ & $4.47(4.38)$ \\
\hline
\end{tabular}


TABLE-2

KEY IR BANDS $\left(\mathrm{cm}^{-1}\right)$ FOR THE TETRAHALOGEN SUBSTITUTED SALAMO-TYPE BISOXIMES $\mathrm{H}_{2} \mathrm{~L}^{1}-\mathrm{H}_{2} \mathrm{~L}^{4}$

\begin{tabular}{ccccccc}
\hline Compound & $v(\mathrm{O}-\mathrm{H})$ & $v(\mathrm{Ar}-\mathrm{O})$ & $v(\mathrm{C}=\mathrm{N})$ & $v(\mathrm{C}-\mathrm{C})_{\text {benzene ring }}$ & $v\left(\mathrm{CH}_{\text {arom }}\right)$ & $v\left(\mathrm{CH}_{2}\right)$ \\
\hline $\mathrm{H}_{2} \mathrm{~L}^{1}$ & 3744 & 1215 & 1604 & $1554,1450,1446$ & 3070 & 2931,2858 \\
$\mathrm{H}_{2} \mathrm{~L}^{2}$ & 3747 & 1209 & 1602 & $1555,1481,1440$ & 3074 & 2941,2858 \\
$\mathrm{H}_{2} \mathrm{~L}^{3}$ & 3743 & 1215 & 1604 & $1553,1512,1461$ & 3074 & 2933,2850 \\
$\mathrm{H}_{2} \mathrm{~L}^{4}$ & 3664 & 1242 & 1604 & $1475,1460,1442$ & 3078 & 2925,2846 \\
\hline
\end{tabular}

TABLE-3

${ }^{1} \mathrm{H}$ NMR DATA FOR THE TETRAHALOGEN SUBSTITUTED SALAMO-TYPE BISOXIMES $\mathrm{H}_{2} \mathrm{~L}^{1}-\mathrm{H}_{2} \mathrm{~L}^{4}$

\begin{tabular}{cll}
\hline Compound & $\pi-\pi^{*}(\mathrm{~nm})$ & \multicolumn{1}{l}{${ }^{1} \mathrm{H} \mathrm{NMR}\left(400 \mathrm{MHz}, \mathrm{DMSO}-\mathrm{d}_{6}, \delta / \mathrm{ppm}\right)$} \\
\hline $\mathrm{H}_{2} \mathrm{~L}^{1}$ & 274,327 & $2.45-2.53(\mathrm{~m}, 10 \mathrm{H}), 4.44(\mathrm{~s}, 4 \mathrm{H}), 7.54(\mathrm{~d}, J=2.0 \mathrm{~Hz}, 2 \mathrm{H}), 7.70(\mathrm{~d}, J=2.2 \mathrm{~Hz}, 2 \mathrm{H}), 8.44(\mathrm{~s}, 2 \mathrm{H}), 9.92(\mathrm{~s}, 2 \mathrm{H})$. \\
$\mathrm{H}_{2} \mathrm{~L}^{2}$ & 274,326 & $2.43-2.52(\mathrm{~m}, 12 \mathrm{H}), 4.43(\mathrm{~s}, 4 \mathrm{H}), 7.53(\mathrm{~d}, J=2.0 \mathrm{~Hz}, 2 \mathrm{H}), 7.71(\mathrm{~d}, J=2.2 \mathrm{~Hz}, 2 \mathrm{H}), 8.45(\mathrm{~s}, 2 \mathrm{H}), 9.83 .02(\mathrm{~s}, 2 \mathrm{H})$. \\
$\mathrm{H}_{2} \mathrm{~L}^{3}$ & 276,328 & $2.43-2.50(\mathrm{~m}, 14 \mathrm{H}), 4.42(\mathrm{~s}, 4 \mathrm{H}), 7.52(\mathrm{~d}, J=2.0 \mathrm{~Hz}, 2 \mathrm{H}), 7.69(\mathrm{~d}, J=2.2 \mathrm{~Hz}, 2 \mathrm{H}), 8.40(\mathrm{~s}, 2 \mathrm{H}), 9.75(\mathrm{~s}, 2 \mathrm{H})$. \\
$\mathrm{H}_{2} \mathrm{~L}^{4}$ & 277,328 & $2.42-2.52(\mathrm{~m}, 16 \mathrm{H}), 4.42(\mathrm{~s}, 4 \mathrm{H}), 7.50(\mathrm{~d}, J=2.0 \mathrm{~Hz}, 2 \mathrm{H}), 7.70(\mathrm{~d}, J=2.2 \mathrm{~Hz}, 2 \mathrm{H}), 8.42(\mathrm{~s}, 2 \mathrm{H}), 9.76(\mathrm{~s}, 2 \mathrm{H})$. \\
\hline
\end{tabular}

appear within $1242-1209 \mathrm{~cm}^{-1}$ as reported for similar bisoxime compounds $^{13}$. These provide evidence for the formation of the title compounds. The $\mathrm{O}-\mathrm{H}$ stretching frequency of the bisoxime compound is expected in the $3300-3800 \mathrm{~cm}^{-1}$ region ${ }^{11}$, here a strong band at $3747-3664 \mathrm{~cm}^{-1}$ was observed in the title compounds $\mathrm{H}_{2} \mathrm{~L}^{1}-\mathrm{H}_{2} \mathrm{~L}^{4}$ and assigned to phenolic alcohol stretching absorption bands. In addition, in the $1555-1440 \mathrm{~cm}^{-1}$ region, the observed bands were attributed to aromatic $\mathrm{C}=\mathrm{C}$ vibrations.

UV-visible spectra and ${ }^{1} \mathbf{H}$ NMR data: The UV-visible spectra of the title compounds $\mathrm{H}_{2} \mathrm{~L}^{1}-\mathrm{H}_{2} \mathrm{~L}^{4}$ in $5 \times 10^{-5} \mathrm{DMF}$ solution are presented in Table-3. UV-visible spectra of the title compounds $\mathrm{H}_{2} \mathrm{~L}^{1}-\mathrm{H}_{2} \mathrm{~L}^{4}$ exhibit two intense peaks at around 274 and $327 \mathrm{~nm}$. The former absorption peak at about $277 \mathrm{~nm}$ can be assigned to the $\pi-\pi^{*}$ transition of the benzene rings, while the latter can be attributed to the intra-ligand $\pi-\pi^{*}$ transition of the $\mathrm{C}=\mathrm{N}$ bonds ${ }^{11,14}$. It is of note that there was no absorption around $400 \mathrm{~nm}$, which is seen in the corresponding Salen derivatives. The absorption is ascribed to the quinoid form of $\mathrm{H}_{2} \mathrm{Salen}^{15}$.

The ${ }^{1} \mathrm{H}$ NMR spectra of the title compounds $\mathrm{H}_{2} \mathrm{~L}^{1}-\mathrm{H}_{2} \mathrm{~L}^{4}$ in DMSO- $\mathrm{d}_{6}$ are shown in Table-3. The ${ }^{1} \mathrm{H}$ NMR spectra showed a singlet at about 8.40-8.44 ppm indicating the the existence of oxime bonds ${ }^{15}$.

\section{Conclusion}

In this paper, a series of variational tetrahalogen substituted Salamo-type compounds $\mathrm{H}_{2} \mathrm{~L}^{1}-\mathrm{H}_{2} \mathrm{~L}^{4}$ that have two oxime bonds instead of imine bonds have been designed and synthesized by the reaction of 2 equivalents of 3-bromo-5-chloro-2hydroxybenzaldehyde with 1,7-bis(aminooxy)heptane, 1,8-bis(aminooxy)octane, 1,9-bis(aminooxy)nonane or 1,10bis(aminooxy)decane under mild conditions, respectively. It is shown that an O-alkyl oxime moiety is much more useful to assemble supramolecular systems than a Schiff base moiety. Further investigation on the synthesis and structures of tetrahalogen substituted Salamo-type complexes with transition metal ions such as copper, manganese, iron, cobalt, nickel and zinc is now in progress.

\section{REFERENCES}

1. J. Kim, B. Chen, T.M. Reineke, H. Li, M. Eddaoudi, D.B. Moler, M. O'Keeffe and O.M. Yaghi, J. Am. Chem. Soc., 123, 8239 (2001).

2. D. Braga, L. Maini, M. Polito, E. Tagliavini and F. Grepioni, Coord. Chem. Rev., 246, 53 (2003).

3. H.Y. Han, Y.L. Song, H.W. Hou, Y.T. Fan and Y. Zhu, J. Chem. Soc., Dalton Trans., 1972 (2006).

4. M.E. Braun, C.D. Steffek, J. Kim, P.G. Rasmussen and O.M. Yaghi, Chem. Commun. (Camb.), 24, 2532 (2001).

5. S.M. Saylor, R.M. Supkowski and R.L. LaDuca, Inorg. Chim. Acta, 361, 317 (2008).

6. J. Kim, B. Chen, T.M. Reineke, H. Li, M. Eddaoudi, D.B. Moler, M. O'Keeffe and O.M. Yaghi, J. Am. Chem. Soc., 123, 8239 (2001).

7. J.P. Costes, F. Dahan and A. Dupuis, Inorg. Chem., 39, 165 (2000).

8. S. Akine, T. Taniguchi and T. Nabeshima, Chem. Lett., 30, 682 (2001).

9. S. Akine, T. Tadokoro and T. Nabeshima, Inorg. Chem., 51, 11478 (2012).

10. S. Akine, S. Hotate and T. Nabeshima, J. Am. Chem. Soc., 133, 13868 (2011).

11. (a) W.K. Dong, Y.X. Sun, C.Y. Zhao, X.Y. Dong and L. Xu, Polyhedron, 29, 2087 (2010); (b) W.K. Dong, Y.X. Sun, Y.P. Zhang, L. Li, X.N. He and X.L. Tang, Inorg. Chim. Acta, 362, 117 (2009); (c) W.K. Dong, X.N. He, H.B. Yan, Z.W. Lv, X. Chen, C.Y. Zhao and X.L. Tang, Polyhedron, 28, 1419 (2009); (d) W.K. Dong, Y.X. Sun, Y.P. Zhang, L. Li, X.N. He and X.L. Tang, Inorg. Chim. Acta, 362, 117 (2009); (e) W.K. Dong, C.Y. Zhao, Y.X. Sun, X.L. Tang and X.N. He, Inorg. Chem. Commun., 12, 234 (2009); (f) W.K. Dong, Y.X. Sun, X.N. He, J.F. Tong and J.C. Wu, Spectrochim. Acta A, 76, 476 (2010); (g) W.K. Dong, S.J. Xing, Y.X. Sun, L. Zhao, L.Q. Chai and X.H. Gao, J. Coord. Chem., 65, 1212 (2012); (h) W.K. Dong, Y.X. Sun, S.J. Xing, Y. Wang and X.H. Gao, Z. Naturforsch, 67b, 197 (2012); (i) W.K. Dong, Y.X. Sun, G.H. Liu, L. Li, X.Y. Dong and X.H. Gao, Z. Anorg. Allg. Chem., 638, 1370 (2012).

12. S. Akine, T. Taniguchi, W. Dong, S. Masubuchi and T. Nabeshima, J. Org. Chem., 70, 1704 (2005).

13. J.A. Faniran, K.S. Patel and J.C. Bailar Jr., J. Inorg. Nucl. Chem., 36, 1547 (1974).

14. T. Ghosh, B. Mondal, T. Ghosh, M. Sutradhar, G. Mukherjee and M. Drew, Inorg. Chim. Acta, 360, 1753 (2007).

15. H.E. Smith, Chem. Rev., 83, 359 (1983). 